\title{
PENERAPAN PEMBELAJARAN KOOPERATIF TIPE THINK PAIR SHARE (TPS) UNTUK MENINGKATKAN KEMAMPUAN PENALARAN MAHASISWA PROGRAM STUDI PENDIDIKAN MATEMATIKA
}

\author{
Alifiani \\ Program Studi Pendidikan Matematika, Universitas Islam Malang \\ alifiani.matematika@yahoo.com
}

\begin{abstract}
ABSTRAK
Berdasarkan kurikulum KKNI (Kerangka Kualifikasi Nasional Indonesia) yang berlaku di Universitas Islam Malang, mata kuliah Struktur Aljabar 1 merupakan matakuliah yang wajib ditempuh oleh mahasiswa semester V Program Studi Pendidikan Matematika Fakultas Keguruan dan Ilmu Pendidikan. Matakuliah Struktur Aljabar 1 berkaitan erat dengan pembuktian, namun mahasiswa Kelas V-C masih mengalami kesulitan dalam pembuktian. Hal ini terlihat dari hasil kuis yang berisi soal-soal pembuktian, hanya $24 \%$ mahasiswa yang mendapatkan nilai di atas 60. Hasil nilai kuis yang kurang memuaskan tersebut terjadi karena kemampuan penalaran mahasiswa yang masih rendah. Oleh karena itu, peneliti tertarik untuk melakukan penelitian dalam rangka meningkatkan kempampuan penalaran mahasiwa dengan menerapkan pembelajaran kooperatif tipe Think Pair Share (TPS).Jenis penelitian merupakan peneltian tindakan kelas. Penelitian dilaksanakan pada kelas VC Program Studi Pendidikan Matematika Universitas Islam Malang yang terdiri dari 25 mahasiswa. Penelitian dilaksanakan dalam 2 siklus, masing-masing siklus terdiri dari 4 pertemuan. Hasil yang didapat adalah pada akhir siklus pertama banyaknya mahasiswa yang mendapat nilai di atas 60 meningkat menjadi $56 \%$ dan di akhir siklus ke 2 banyaknya mahasiswa yang mendapat nilai di atas 60 meningkat menjadi 84\%. Berdasarkan hasil penelitian diketahui bahwa pembelajaran kooperatif tipe Think Pair Share (TPS) dapat meningkatkan kemampuan penalaran mahasiswa dalam melakukan pembuktian.
\end{abstract}

Kata kunci: Pembelajaran Kooperatif, Think Pair Share (TPS), Kemampuan Penalaran, Penelitian Tindakan Kelas

\section{PENDAHULUAN}

Matematika terbangun dari proses penalaran dan pembuktian, bukan hanya kumpulan dari sebarang aturan (Stacey dan Vincent, 2009). Hal ini didukung oleh Byres (2007) bahwa pembuktian matematis, teori matematika, dan penalaran logis merupakan dasar dari matematika formal. Pembuktian berkaitan erat dengan penalaran, bahkan Brodie (2010) menyatakan bahwa penalaran matematis dapat disamakan dengan pembuktian. Pembuktian 
yang valid merupakan hasil konstruksi dari penalaran yang tepat (Ayalon dan Even, 2008). Menurut Stylianides dan Stylianides (2009) pembuktian merupakan inti dari belajar matematika sehingga siswa harus dibekali dengan kemampuan penalaran pada setiap jenjang pendidikan. Oleh karena itu, penalaran dan pembuktian harus dilibatkan dalam pembelajaran matematika di setiap jenjang pendidikan termasuk pada jenjang Perguruan Tinggi.

Berdasarkan Kurikulum KKNI (Kerangka Kualifikasi Nasional Indonesia) yang berlaku di Universitas Islam Malang, mata kuliah Struktur Aljabar 1 merupakan mata kuliah yang wajib ditempuh oleh mahasiswa semeseter V Program Studi Pendidikan Matematika Fakultas Keguruan dan Ilmu Pendidikan. Secara umum, Struktur Aljabar 1 membahas tentang teori grup dan strukturnya. Struktur Aljabar 1 termasuk dalam ilmu aljabar modern. Sejak abad ke-19 matematikawan menyadari bahwa simbol tidak hanya untuk melambangkan bilangan seperti pada aljabar klasik, sehingga lahir ilmu aljabar modern (Gilbert dan Nicholson, 2004). Aljabar modern jarang sekali melibatkan angka sebagai lambang bilangan sehingga sering disebut sebagai aljabar abstrak. Menurut Gilbert dan Gilbert (2009), aljabar abstrak digunakan dalam upaya mencari generalisasi dari permasalahan yang spesifik. Berdasarkan solusi dari permasalahan tertentu, teknik umum berkembang dalam menyelesaikan permasalahan sejenis, akhirnya teknik pemecahan masalah dapat digeneralisasi pada seluruh permasalahan sejenis. Dalam upaya melakukan generalisasi diperlukan proses pembuktian dan penalaran agar generalisasi yang dibuat valid. Oleh karena itu Struktur Aljabar 1 sebagai ilmu aljabar abstrak berkaitan erat dengan pembuktian dan penalaran.

Fakta yang didapat peneliti selama mengajar di Kelas V-C Program Studi Pendidikan Matematika Universitas Islam Malang, kemampuan generalisasi mahasiswa masih kurang. Mahasiswa belum dapat membuktikan bahwa generalisasi valid untuk seluruh permasalahan sejenis. Hal ini terlihat dari hasil kuis mahasiswa pada matakuliah Struktur Aljabar 1 yang kurang memuaskan, hanya 6 mahasiswa dari keseluruhan 25 mahasiswa atau hanya 24\% mahasiswa yang mendapat nilai di atas 60. Kuis berisi soal pembuktian bahwa apabila operasi biner (*) didefinisikan untuk setiap elemen pada himpunan $G$, maka $G$ adalah grup Abelian terhadap operasi biner (*). Syarat bahwa G grup Abelian terhadap operasi biner (*) adalah: 1) G tertutup dalam operasi biner (*), 2) operasi biner (*) asosiatif, 3) G memuat elemen identitas, 4) setiap elemen $G$ memiliki invers, 5) operasi biner (*) komutatif (Gilbert dan Gilbert, 2009). Permasalahan yang terjadi adalah dalam menunjukkan 5 syarat tersebut, mahasiswa seringkali menggunakan contoh. Padahal jika hanya dengan contoh, belum tentu berlaku secara general untuk seluruh elemen himpunan G. Selain soal pembuktian bahwa G adalah grup Abelian, kuis juga memuat soal pembuktian teorema. Permasalahan yang terjadi pun sama, mahasiswa membuktikan dengan cara memberikan contoh. Hal ini menunjukkan bahwa kemampuan penalaran mahasiswa dalam melakukan pembuktian masih rendah. 
Dalam hal membuktikan teorema maupun membuktikan bahwa $G$ grup Abelian diperlukan proses penalaran deduktif, artinya proses penalaran dari umum ke khusus, yaitu membuktikan pernyataan matematis yang ada dan menunjukkan generalitas dari pernyaataan tersebut (Ayalon dan Even, 2008). Pembuktian dapat dilakukan dengan beberapa metode, diantaranya bukti langsung, bukti tak langsung (kontradiksi), induksi matematik, maupun metode bagi kasus (Sundstrom, 2014). Salah satu upaya untuk meningatkan kemampuan penalaran mahasiswa adalah dengan pembelajaran kooperatif. Menurut Vygotsky (dalam Slavin, 2006) pembelajaran kooperatif membuat penalaran yang ada dalam pikiran mahasiswa dapat dikomunikasikan dengan mahasiswa lain sehingga dapat saling memahami proses penalaran masing-masing. Dengan demikian kemampuan penalaran mahasiswa akan meningkat. Hal ini dibuktikan oleh Kramarski dan Mevarech (2003) bahwa peningkatan kemampuan penalaran mahasiswa yang belajar melalui model pembelajaran kooperatif lebih tinggi dibanding mahasiswa yang belajar melalui model pembelajaran individual.

Salah satu tipe pembelajaran kooperatif adalah model pembelajaran Think Pair Share (TPS). Think Pair Share (TPS) merupakan jenis pembelajaran kooperatif yang dirancang dalam bentuk diskusi secara berpasangan yang dapat meningkatkan kemampuan penalaran, keterampilan berkomunikasi, dan mendorong partisipasi siswa dalam kelas (Azlina, 2010). Pembagian kelompok siswa secara berpasangan menunjukkan pencapaian yang jauh lebih besar dalam bidang ilmu pengetahuan daripada kelompok yang terdiri atas empat atau lima orang (Slavin, 2010). Diskusi dalam bentuk kelompok kecil sangat efektif untuk memudahkan mahasiswa dalam memahami materi dan memecahkan suatu permasalahan (Septriana dan Handoyo, 2006). Salah satu keunggulan dari TPS adalah mudah untuk diterapkan pada berbagai tingkat kemampuan berpikir dan dalam setiap kesempatan (Septriana dan Handoyo, 2006). Siswa diberi waktu lebih banyak berpikir, menjawab, dan saling membantu satu sama lain. Prosedur yang digunakan juga cukup sederhana. Bertanya kepada teman sebaya dan berdiskusi kelompok dapat membantu mahasiswa untuk mendapatkan kejelasan terhadap suatu materi. Oleh karena itu, peneliti menerapkan model pembelajaran kooperatif tipe Think Pair Share (TPS) dalam rangka meningkatkan kemampuan penalaran mahasiswa Kelas V-C Universitas Islam Malang pada Mata Kuliah Struktur Aljabar 1.

\section{METODE}

Penelitian ini termasuk dalam jenis penelitian tindakan kelas (PTK). Penelitian dilakukan di Universitas Islam Malang yang terletak di Jalan MT Haryono 193 Malang. Waktu penelitian Oktober - Januari 2016. Peneliti bertindak sebagai dosen pengajar. Subjek penelitian yang digunakan dalam penelitian ini adalah seluruh siswa kelas V-C Pendidikan Matematika Universitas Islam Malang semester gasal Tahun 2015/2016 yang terdiri dari 25 mahasiswa, yaitu 3 mahasiswa laki-laki dan 22 mahasiswa perempuan. Pendekatan penelitian yang digunakan dalam penelitian ini adalah pendekatan kualitatif karena bertujuan untuk mendeskripsikan penerapan model pembelajaran kooperatif tipe TPS dalam meningkatkan 
kemampuan penalaran mahasiswa kelas V-C Pendidikan Matematika Universitas Islam Malang. Berdasarkan jenis dan pendekatan penelitian, kehadiran peneliti di lapangan mutlak diperlukan karena peneliti bertindak sebagai pengajar dan pengumpul data.

PTK ini dilaksanakan dalam 2 siklus. Masing-masing siklus terdiri dari 4 pertemuan. Menurut Kurt Lewis (dalam Susilo, 2009) setiap siklus PTK terdiri dari perencanaan, pelaksanaan tindakan, observasi, dan refleksi. Secara garis besar pelaksanaan penelitian ini dapat digambarkan sebagai berikut.

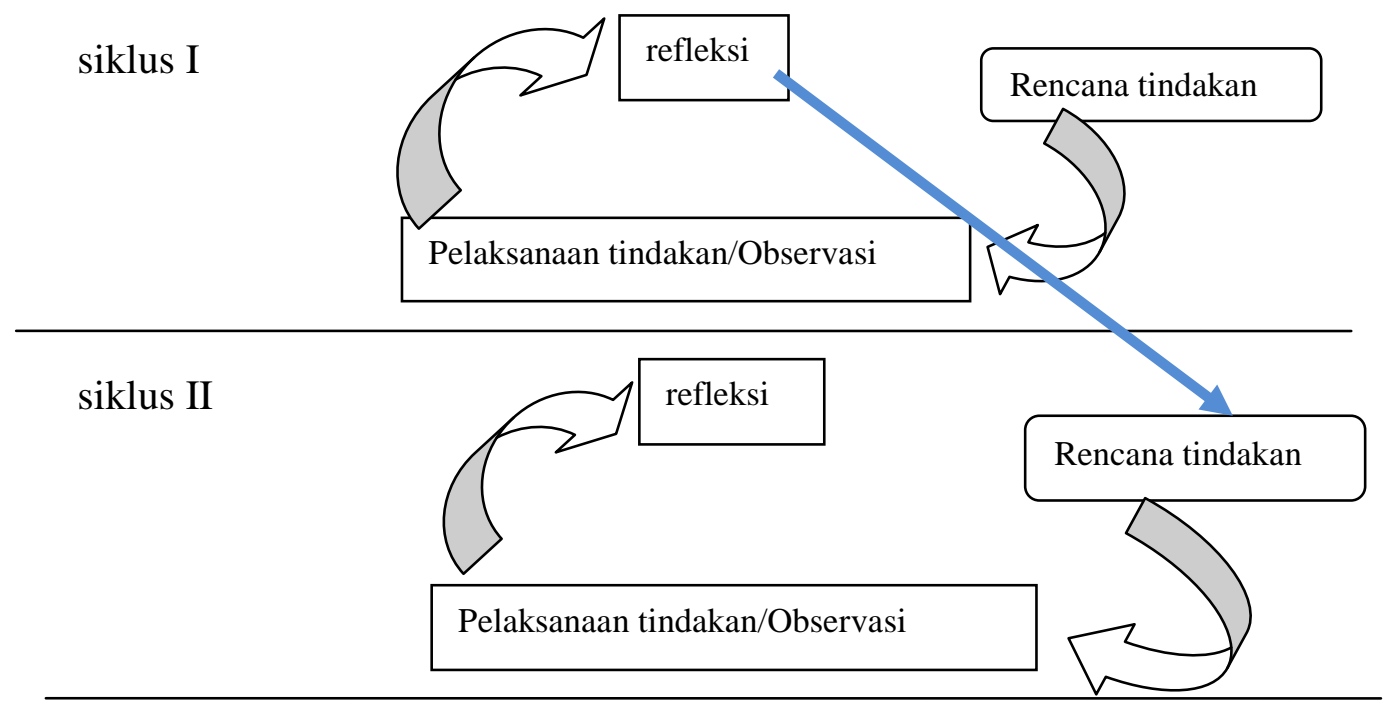

Gambar 1. Siklus Penelitian Tindakan Kelas yang dikembangkan oleh Kurt Lewis (dalam Susilo, 2009)

Semua proses dan hasil pembelajaran yang dilakukan oleh peneliti direkam dalam suatu catatan yang disebut catatan lapangan. Hasil catatan lapangan selanjutnya digunakan sebagai acuan perencanaan tindak lanjut pada siklus berikutnya. Tindakan yang dilakukan pada siklus kedua merupakan perbaikan dari siklus satu, sedangkan hal-hal yang sudah baik dipertahankan.

\section{HASIL}

\section{Siklus 1}

Penerapan pembelajaran kooperatif tipe TPS pada siklus 1 membahas materi subgroup dan grup siklik. Dalam setting pembelajaran kooperatif tipe TPS, mahasiswa membahas tugas dalam kelompok yang terdiri dari 2 orang, kemudian tugas dibahas bersama dalam diskusi kelas dimana ada satu perwakilan kelompok yang mempresentasikan hasil diskusinya. Tugas berisi pembuktian teorema dan contoh soal pembuktian, diantaranya adalah pembuktian subgroup. Dalam membuktikan subgroup ada 3 metode yang dapat digunakan, yaitu pembuktian dengan menggunakan Definisi, Teorema 1, dan Teorema 2. Adapun penjelasan dari 3 metode tersebut adalah sebagai berikut.

1. Definisi Subgrup 
Jika $\mathrm{G}$ adalah grup terhadap operasi biner *. Himpunan bagian $\mathrm{H}$ dari $\mathrm{G}$ disebut subgroup $\mathrm{G}$ jika $\mathrm{H}$ merupakan group terhadap operasi biner * yang terdefinisi pada $\mathrm{G}$.

2. Teorema 1

Himpunan bagian $\mathrm{H}$ dari grup $\mathrm{G}$ adalah subgrup $\mathrm{G}$ jika dan hanya jika 3 kondisi berikut terpenuhi:
a. $\mathrm{H}$ tidak kosong
b. $\mathrm{x} \in \mathrm{H}$ dan $\mathrm{y} \in \mathrm{H}$ mengakibatkan $\mathrm{xy} \in \mathrm{H}$; and
c. $\mathrm{x} \in \mathrm{H}$ mengakibatkan $\mathrm{x}^{-1} \in \mathrm{H}$.

3. Teorema 2

Himpunan $\mathrm{H}$ dari grup $\mathrm{G}$ adalah subgroup $\mathrm{G}$ jika dan hanya jika

a. H tidak kosong, dan

b. $\mathrm{a} \in \mathrm{H}$ dan $\mathrm{b} \in \mathrm{H}$ mengakibatkan $\mathrm{ab}^{-1} \in \mathrm{H}$.

Dalam setting pembelajaran kooperatif tipe TPS yang diterapkan dalam siklus 1, telah dibahas pembuktian dari Teorema 1 dan Teorema 2 serta contoh soal pembuktian subgroup. Permasalahan yang terjadi adalah ada beberapa mahasiswa yang tidak memperhatikan diskusi kelas. Meski demikian, hasil tes siklus 1 sudah menunjukkan adanya peningkatan, dari hanya ada 6 mahasiswa (24\%) yang mendapatkan nilai di atas 60 menjadi 14 mahasiswa (56\%) yang mendapat nilai di atas 60. Mahasiswa juga sudah mulai melakukan generalisasi dalam membuktikan subgroup, tidak lagi dengan contoh. Permasalahan yang terjadi saat dilakukan tes siklus 1 yaitu masih ada mahasiwa yang membuktikan subgroup dengan menggunakan Teorema, tetapi langkah pembuktiannya sesuai dengan langkah pembuktian Teorema. Padahal, jika Teorema sudah dibuktikan maka Teorema tersebut sudah dapat digunakan sebagai dasar pembuktian, tanpa perlu dilakukan langkah pembuktian Teorema kembali. Hal ini menandakan bahwa masih ada mahasiswa yang hanya melakukan langkah prosedural tanpa melakukan proses penalaran dalam membuktikan subgroup.

\section{Siklus 2}

Di awal penerapan siklus 2, peneliti membahas permasalahan yang terjadi berdasar hasil tes siklus 1. Peneliti memberi umpan balik pada diskusi kelas tentang penggunaan Teorema. Kemudian dilanjutkan dengan penerapan pembelajaran kooperatif tipe TPS dalam materi Grup Permutasi, Koset, dan Subgrup Normal. Penerapan pembelajaran kooperatif tipe TPS yang diterapkan hampir sama seperti pada siklus pertama yaitu, mahasiswa membahas tugas dalam kelompok yang terdiri dari 2 orang, kemudian tugas dibahas bersama dalam diskusi kelas dimana ada satu perwakilan kelompok yang mempresentasikan hasil diskusinya. Tugas berisi pembuktian teorema dan contoh soal pembuktian. Perbedaannya dalam diskusi kelas, peneliti menunujuk mahasiswa secara acak untuk mengerjakan soal pembuktian di depan kelas. Hal ini dimaksudkan agar setiap mahasiswa memperhatikan diskusi kelas dan siap apabila sewaktu-waktu diminta mengerjakan soal di depan kelas. Hasil tes siklus 2 kembali menunjukkan adanya peningkatan, dari 14 mahasiswa (56\%) yang mendapat nilai di 
atas 60 pada siklus pertama menjadi ada 21 mahasiswa (84\%) yang mendapat nilai di atas 60 . Hal ini menunjukkan bahwa kemampuan penalaran mahasiswa meningkat.

\section{PEMBAHASAN}

Berdasarkan hasil penelitian, didapat bahwa terjadi peningkatan hasil tes dari siklus 1 dan siklus 2. Tes siklus 1 dan tes siklus 2 berisi tentang soal-soal pembuktian untuk mengukur kemampuan penalaran mahasiswa. Oleh karena itu, dapat disimpulkan bahwa kemampuan penalaran mahasiswa meningkat dengan diterapkannya pembelajaran kooperatif tipe Think Pair Share (TPS) sesuai dengan pendapat Vygotsky (dalam Slavin 2010) dan Kramarski dan Mevarech (2003) bahwa pembalajaran kooperatif lebih efektif dibanding pembelajaran individual dalam meningkatkan kemampuan penalaran karena pembelajaran kooperatif membuat penalaran yang ada dalam pikiran mahasiswa dapat dikomunikasikan dengan mahasiswa lain sehingga dapat saling memahami proses penalaran masing-masing. Tipe Think Pair Share (TPS) juga terbukti lebih efektif dalam meningkatkan kemampuan penalaran mahasiswa. Diskusi kelompok yang terdiri dari dua orang membuat seluruh anggota kelompok aktif berdiskusi sesuai dengan pendapat Slavin (2010). Pada akhirnya, pembelajaran kooperatif tipe Think Pair Share (TPS) yang dirancang dalam bentuk diskusi secara berpasangan terbukti mampu meningkatkan kemampuan penalaran mahasiswa dalam kelas sesuai pendapat Azlina (2010).

\section{SIMPULAN DAN SARAN}

\section{Kesimpulan}

Pembelajaran kooperatif tipe Think Pair Share (TPS) terbukti mampu meningkatkan kemampuan penalaran mahasiswa Pendidikan Matematika Universitas Islam Malang kelas V-C pada Mata Kuliah Struktur Aljabar 1.

\section{Saran}

Bagi peneliti lain disarankan untuk menerapkan pembelajaran kooperatif tipe Think Pair Share (TPS) untuk meningkatkan kemampuan penalaran dalam materi lain dan kelas lain dalam berbagai jenjang pendidikan guna mengembangkan penelitian ini.

\section{DAFTAR RUJUKAN}

Ayalon, M. dan Even, M. 2008. Deductive reasoning: in the eye of the beholder. Educational Studies in Mathematics, 69: 235-247.

Azlina, N.A.N. 2010. CETLs : Supporting Collaborative Activities Among Students and Teachers Through the Use of Think-Pair-Share Techniques. International Journal of Computer Science Issues, 7 (5): 18-29.

Brodie, K. 2010. Teaching Mathematical Reasoning in Secondary School Classrooms. New York: Springer.

Byres, W. 2007. How Mathematicians Think. New Jersey: Princeton University Press. 
Gilbert, L. dan Gilbert, J. 2009. Elements of Modern Algebra (Seventh Edition). Singapore: Brooks/ Cole.

Gilbert, W.J. dan Nicholson, W.K. 2004. Modern Algebra with Applications (Second Edition). New Jersey: John Wiley \& Sons, Inc.

Kramarski, B. dan Mevarech, Z.R. 2003. Enhancing Mathematical Reasoning in the Classroom: The Effects of Cooperative Learning and Metacognitive Training. American Education Research Journal 40 (1): 281-312

Septriana, N. dan Handoyo, B. 2006. Penerapan Think Pair Share (TPS) dalam Pembelajaran Kooperatif untuk Meningkatkan Prestasi Belajar Geografi. Jurnal Pendidikan Inovatif, 2 (1): 47 -50.

Slavin, R.E. 2006. Educational Psychology: Theory and Practice (Eight edition). Pearson: Singapore.

Slavin, R.E. 2010. Cooperative Learning: Applying Contact Theory in Desegrated Schools. Journal of Social Issues, 41 (3): 45-62.

Stacey, K. dan Vincent, J. 2009. Modes of reasoning in explanations in Australian eighthgrade mathematics textbooks. Educational Studies in Mathematics, 72: 271-288.

Stylianides, A.J. dan Stylianides, G.J. 2009. Proof constructions and evaluations. Educational Studies in Mathematics, 72: 271-288.

Sundstrom, T. 2014. Mathematical Reasoning: Writing and Proof. California: Creative Commons.

Susilo, Herawati, Chotimah, H, Sari,Y.D. 2009. Penelitian Tindakan Kelas. Sebagai Sarana Pengembangan Keprofesionalan Guru dan Calon Guru. Malang: Bayumedia. 